\title{
Delineando o valor do sistema de informação de uma organização
}

\author{
Eduardo Amadeu Dutra Moresi \\ Doutorando em Ciência da Informação (UnB). \\ e.moresi@base.com.br
}

\section{Resumo}

Inicialmente, são explorados conceitos sobre o valor da informação, buscando responder às seguintes questões: a finalidade da informação para uma organização, a classificação de seus tipos de valor e o seu valor econômico. É apresentada uma análise sobre os níveis hierárquicos da informação no processo decisório de uma organização, que são os seguintes: dados, informação, conhecimento e inteligência. A seguir, é feita uma análise sobre o valor de um sistema de informação, baseando-se em uma equação metafórica composta dos seguintes fatores: portifólio de produtos e serviços, qualidade, custo e tempo de resposta. Por fim, são analisados aspectos relativos ao planejamento e à cadeia de valor de um sistema de informação.

\section{Palavras-chave}

Valor da informação; Hierarquia da informação; Valor do sistema de informação; Cadeia de valor de sistema de informação.

\section{Delineating the value of the information system of an organization}

\begin{abstract}
First, the concepts about information value are carefully examined, seeking an answer to the following questions: what is the purpose of information for an organization, how are the types of falue classified and what is its economic value? An analysis is presented about the hierarchical information levels in the decision-making process of an organization as follows: data, information, knowledge and intelligence. An analysis is made about the value of information system, based on a methaphorical equation made out of the following factors: portfolio of products and services, quality, cost and replying time. Aspects related to planning are also analysed, as well as the chain of value of information system.
\end{abstract}

\section{Keywords}

Information value; Information hierarchy; Information system value; Information system value chain.

Artigo aceito para publicação em 12/05/2000

\section{INTRODUÇÃO}

Hoje em dia, existe o consenso de que na sociedade pósindustrial, cuja economia assume tendências globais, a informação passou a ser considerada um capital precioso equiparando-se aos recursos de produção, materiais e financeiros. O que tem sido relevante é a mudança fundamental no significado que a informação assume na nova realidade mundial de uma sociedade globalizada: agora a informação não é apenas um recurso, mas o recurso. A aceitação desta idéia a coloca como o recursochave de competitividade efetiva, de diferencial de mercado e de lucratividade nesta nova sociedade.

A importância da informação para as organizações é universalmente aceita, constituindo, senão o mais importante, pelo menos um dos recursos cuja gestão e aproveitamento estão diretamente relacionados com o sucesso desejado. A informação também é considerada e utilizada em muitas organizações como um fator estruturante e um instrumento de gestão. Portanto, a gestão efetiva de uma organização requer a percepção objetiva e precisa dos valores da informação e do sistema de informação.

Inicialmente, este artigo explora aspectos relativos ao valor da informação, buscando responder a questões sobre a finalidade da informação para uma organização, a classificação de seus tipos de valor e o seu valor econômico. São apresentados, também, um conceito de informação, considerado mais adequado a esta abordagem, bem como os tipos de informação no contexto de uma organização.

Para que se possa reforçar estes aspectos relativos ao valor da informação, é apresentada uma análise sobre os níveis hierárquicos da informação no processo decisório de uma organização. Os quatro níveis abordados são os seguintes: dados, informação, conhecimento e entendimento (Urdaneta,1992).

A seguir, é feita uma análise sobre o valor de um sistema de informação, baseando-se em uma equação metafórica composta dos seguintes fatores: portifólio de produtos e serviços, qualidade, custo e tempo de resposta. Por fim, são analisados aspectos relativos ao planejamento de desenvolvimento e a cadeia de valor de um sistema de informação. 


\section{A INFORMAÇÃO NO CONTEXTO DAS ORGANIZAÇÕES}

A aceitação de que a informação possua um valor da mesma forma que outros recursos da organização é, ainda, um assunto polêmico. As diferenças da informação em relação a outros recursos dificultam ou impossibilitam a sua categorização em termos econômicos. Estas dificuldades motivam as organizações, como alternativa ao gerenciamento da informação, a direcionar os seus esforços de gestão sobre as tecnologias da informação (King \& Kraemer, 1988), por encontrarem aí maior aplicabilidade de seus modelos tradicionais.

Basicamente, a informação tem duas finalidades: para conhecimento dos ambientes interno e externo de uma organização e para atuação nestes ambientes (Chaumier, 1986). Uma derivação desta classificação deve ser feita em função do papel que a informação pode desempenhar nas atividades de uma organização (informação crítica, mínima, potencial, sem interesse), conforme é apresentado na figura 1.

Reconhecendo a importância da informação, muitas organizações não são sensíveis a alguns excessos na busca e na manutenção da informação. Os esforços principais de uma organização devem priorizar a busca e a manutenção da informações crítica, mínima e potencial, respectivamente. Em relação à informação sem interesse, o esforço é, obviamente, no sentido de se evitar desperdício de recursos na sua obtenção. A aceitação do princípio subjacente a classificações como esta é comum e utilizado em muitas abordagens de gerenciamento da informação. Contudo, a operacionalização deste princípio é muito delicada, pois a classificação de uma dada informação, em particular, em uma destas classes é, obviamente, um problema de difícil resolução prática.

Para minimizar esta dificuldade na classificação, é imprescindível compreender um outro princípio, o do valor da informação. Antes disso, é preciso definir qual o conceito aqui adotado para o termo informação. Saracevic (1999) ressalta que informação tem uma variedade de conotações em diferentes campos. Em alguns campos, incluindo a ciência da informação, a noção de informação está geralmente associada às mensagens. Nesse sentido, existe um grande número de interpretações que são assumidas em diferentes abordagens teóricas e práticas para o tratamento da informação. Barreto (1996) define o termo informação da seguinte maneira: estruturas significantes com a competência de gerar conhecimento no indivíduo, em seu grupo, ou a sociedade. Trata-se de um conceito muito interessante, devido à profundidade $\mathrm{e}$ abrangência alcançados.
FIGURA 1

A classificação da informação segundo a sua finalidade para uma organização (adaptada de Amaral, 1994).

Informação sem interesse

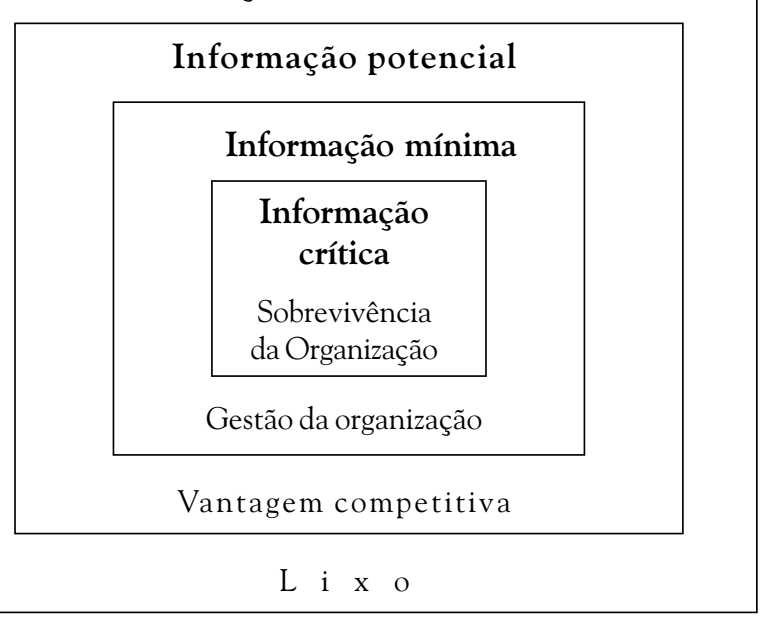

Entretanto, no contexto deste trabalho, a partir do conceito acima, adotar-se-á o seguinte constructo, menos abrangente e mais focado para as organizações: estruturas significantes com a competência de gerar conhecimento no indivíduo ou em sua organização.

No contexto de uma organização, a informação deve atender às necessidades dos diversos níveis administrativos. Em geral, as organizações diferenciamse em três níveis organizacionais (Chiavenatto, 1999), qualquer que seja a natureza ou tamanho da organização:

- operacional - relacionado com os problemas de desempenho eficaz e dirigido para as exigências impostas pela natureza da tarefa técnica;

- intermediário ou gerencial - gerencia particularmente as atividades do nível operacional, mediando as fronteiras ambientais e administrando as tarefas técnicas que devem ser desempenhadas, escala de operações etc.;

- institucional - constitui-se na fonte do significado e da legitimização que possibilita a consecução dos objetivos organizacionais.

O institucional corresponde ao nível mais elevado da empresa, composto dos diretores, dos proprietários ou acionistas e dos altos executivos. É o nível em que as decisões são tomadas e são estabelecidos os objetivos da organização, bem como as estratégias para alcançá-los. Mantém a interface com o ambiente, lidando com a 
incerteza, exatamente pelo fato de não ter poder ou controle algum sobre os eventos ambientais presentes e muito menos capacidade de prever com razoável precisão os eventos ambientais futuros.

O nível intermediário, também chamado de nível mediador, nível gerencial ou nível organizacional, é aquele posicionado entre o institucional e o operacional que cuida da articulação interna entre eles. Trata-se da linha do meio de campo. Cuida também da escolha e captação dos recursos necessários, bem como da distribuição e colocação do que foi produzido pela empresa nos diversos segmentos do mercado. Este é o nível que lida com os problemas de adequação das decisões tomadas em nível institucional (no topo) com as operações realizadas em nível operacional (na base da organização). O nível intermediário é geralmente composto da média administração da empresa, isto é, as pessoas ou órgãos que transformam as estratégias elaboradas para atingir os objetivos empresariais em programas de ação. O nível institucional está geralmente ligado ao nível operacional por uma cadeia de administradores de linha média com autoridade formal.

O nível operacional, também denominado nível técnico ou núcleo técnico, está localizado nas áreas inferiores da organização. Está relacionado com os problemas ligados à execução cotidiana e eficiente das tarefas e operações da organização e orientado quase exclusivamente para as exigências impostas pela natureza da tarefa técnica a ser executada, com os materiais a serem processados e com a cooperação de numerosos especialistas necessários ao andamento dos trabalhos. É o nível no qual as tarefas são executadas e as operações realizadas: envolve o trabalho básico relacionado diretamente com a produção dos produtos ou serviços da organização.

Esse nível é geralmente composto pelas áreas encarregadas de programar e executar as tarefas e operações básicas da organização. É nele que estão as máquinas e equipamentos, as instalações físicas, as linhas de montagem, os escritórios, os balcões de atendimento, cujo funcionamento deve atender a determinadas rotinas e procedimentos programados dentro de uma regularidade e continuidade que assegurem a utilização plena dos recursos disponíveis e a máxima eficiência das operações.

Portanto, a informação deve atender a necessidades diferenciadas de cada um de seus níveis. Nesse caso, a arquitetura de informação de uma organização compreende a seguinte tipologia:
- a informação de nível institucional possibilita, ao nível institucional, observar as variáveis presentes nos ambientes externo e interno, com a finalidade de monitorar e avaliar o desempenho, o planejamento e as decisões de alto nível;

- a informação de nível intermediário permite ao nível intermediário observar variáveis presentes nos ambientes externo e interno, monitorar e avaliar seus processos, o planejamento e a tomada de decisão de nível gerencial;

- a informação de nível operacional possibilita ao nível operacional executar as suas atividades e tarefas, monitorar o espaço geográfico sob sua responsabilidade, o planejamento e a tomada de decisão de nível operacional.

\section{O VALOR DA INFORMAÇÃO}

Como é possível admitir que a informação possua valor, é preciso definir parâmetros capazes de quantificá-lo, o que não é uma tarefa trivial. Uma das maneiras é realizada por meio dos juízos de valor, que, apesar de serem indefinidos, consideram que o valor varia de acordo com o tempo e a perspectiva. Podem, em certos casos, ser negativos, como acontece na sobrecarga de informação.

Sob esta perspectiva, o valor da informação pode ser classificado nos seguintes tipos (Cronin, 1990):

- valor de uso: baseia-se na utilização final que se fará com a informação;

- valor de troca: é aquele que o usuário está preparado para pagar e variará de acordo com as leis de oferta e demanda, podendo também ser denominado de valor de mercado;

- valor de propriedade, que reflete o custo substitutivo de um bem;

- valor de restrição, que surge no caso de informação secreta ou de interesse comercial, quando o uso fica restrito apenas a algumas pessoas.

Muitas vezes não é possível quantificar o valor da informação estabelecendo uma equivalência a uma quantia em dinheiro. Por ser um bem abstrato e intangível, o seu valor estará associado a um contexto. Assim, os valores de uso e de troca poderão ser úteis na definição de uma provável equivalência monetária. 
Por exemplo, uma empresa que atua em bolsa de mercadorias, mais especificamente no mercado futuro, terá grande interesse em informações relativas à produção agrícola de um determinado país ou região. Esta empresa, provavelmente, irá alocar recursos na busca sistemática deste tipo de informação, que será utilizada na determinação de indicadores de uma tendência e que fundamentará decisões sobre o tipo de investimento a ser realizado, caracterizando a importância dos valores de uso e de troca. Considerando que, a partir delas, poderá ser obtido algum tipo de vantagem competitiva ou de diferencial de mercado, estas informações assumirão um valor de restrição, para que se possa preservar o sigilo da aplicação.

Por outro lado, uma organização governamental ou não que realize censos demográficos, de estilo de vida ou algum outro tipo de pesquisa de acompanhamento, deverá manter, por razões legais, o armazenamento de dados e séries históricas sem que haja explícita intenção de exploração ou de uso. Neste caso, a informação terá um valor de propriedade.

O ponto principal é perceber a informação pertencendo a dois domínios (Van Wegen \& De Hoog, 1996). No primeiro deles, ela deve atender às necessidades de uma pessoa ou de um grupo. Nesse caso, a disponibilização da informação deve satisfazer os seguintes requisitos:

- ser enviada à pessoa ou ao grupo certos;

- na hora certa e no local exato;

- na forma correta.

O segundo domínio é o da organização, que introduz questões a respeito da determinação do valor da informação. Neste contexto, o valor da informação está relacionado ao seu papel no processo decisório. A determinação do valor somente do conteúdo parece um corolário natural do uso da informação como um insumo da tomada de decisão. Entretanto, ainda que a informação adquira seu valor a partir de seu papel na tomada de decisão, o produto informacional como um todo também agrega valor a outras atividades no processamento da informação.

Cabe então uma questão: a informação possui um valor econômico? Ela terá valor econômico quando levar à satisfação dos desejos humanos. Uma pequena parcela da informação disponível constitui-se em produtos finais, ou seja, aqueles que são consumidos diretamente pelas pessoas, cujo valor deriva-se da oferta e da procura. A porção majoritária, porém, cabe aos bens intermediários, que são aqueles que conduzem a outros bens e serviços. Neste caso, o valor estará diretamente relacionado ao dos bens e serviços que deles se utilizam (Dertouzos, 1997).

Da mesma forma, a informação terá valor econômico para uma organização, se ela gerar lucros ou for alavancadora de vantagem competitiva. Cronin (1990) afirma que, de modo geral, a percepção de valor pode ser influenciada pelos seguintes fatores:

- identificação de custos;

- entendimento da cadeia de uso;

- incerteza associada ao retorno dos investimentos em informação;

- dificuldade de se estabelecerem relações causais entre os insumos de informação e produtos específicos;

- tradição de se tratar a informação como uma despesa geral;

- diferentes expectativas e percepções dos usuários;

- fracasso em reconhecer o potencial comercial e o significado da informação.

Para concluir este item, é importante reconhecer que, de modo geral, poucas decisões são tomadas com informação perfeita, devido a alguma insuficiência de informação e/ ou uma sobrecarga de informação desnecessária. $O$ valor da informação é uma função do efeito que ela tem sobre o processo decisório. Se a informação adicional resultar em uma decisão melhor, então ela terá valor. Caso contrário, ela terá pouco ou nenhum valor (Wetherbe, 1987). A figura 2 sintetiza estes aspectos, mostrando que uma mesma informação poderá ter valor diferenciado, dependendo do contexto da organizações.

FIGURA 2

O valor da informação depende do contexto da organização

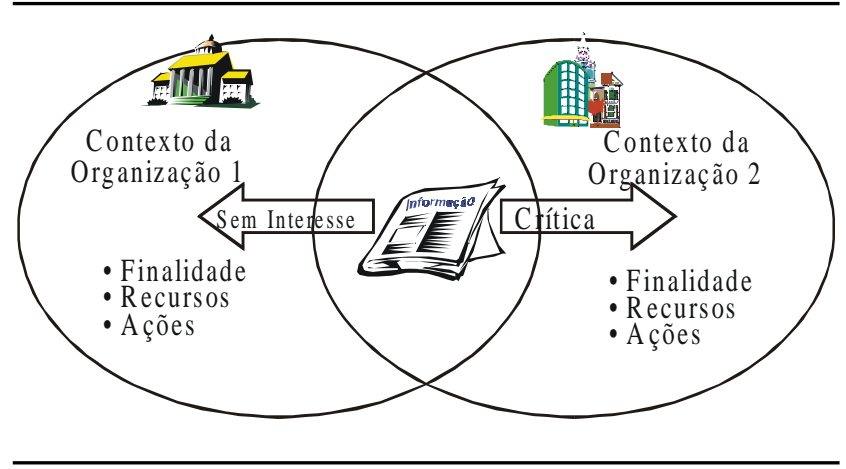


Assim, o valor da informação pode ser traduzido em uma equação que contenha todos os fatores que influenciam a avaliação de valor da informação. É preciso definir quem é o cliente, qual a finalidade de utilização da informação, a que nível organizacional atenderá à necessidade, qual a utilidade para outros clientes e os resultados esperados. Portanto, a figura 3 apresenta uma ilustração desta equação que procura resumir a função que define o valor da informação (VI).

\section{OS NÍVEIS HIERÁRQUICOS DA INFORMAÇÃO NO PROCESSO DECISÓRIO DE UMA ORGANIZAÇÃO}

A atividade máxima de qualquer executivo, independentemente de seu posicionamento hierárquico em uma organização, é a tomada de decisão. Este é o momento no qual ele demonstra toda a sua capacidade de conduzir os seus subordinados e sua razão de ser dentro dela. Os executivos passam grande parte do seu tempo estudando o ambiente e procurando identificar as possíveis linhas de ação. A tomada de decisão é muito mais do que o momento final da escolha, sendo um processo complexo de reflexão, investigação e análise.

No processo decisório, o volume de informações e dados colocados à disposição do decisor deve ser na medida certa. Se este volume for excessivo, os dados e informações pertinentes à solução do problema serão mascarados por aqueles considerados expúrios. Para resolver este problema, é necessário escalonar a informação em uma hierarquia capaz de diferenciar as necessidades nas diversas situações, o que reforça a importância de reconhecer que a informação possui valor.

Genericamente, o termo informação é usado para se referir a todas as maneiras de descrições ou representações de sinais ou dados. Mas é importante reconhecer que existem, de fato, quatro classes diferentes de informação, que são as seguintes: dados, informação, conhecimento e inteligência (Urdaneta, 1992). Então, é preciso entender as diferenças entre estas classes, porque elas possuem valores diferentes no contexto do processo decisório. Os altos escalões de uma organização ou de uma empresa necessitam de informação qualitativa, que contenha um alto valor agregado, para que se possa obter uma visão global da situação. Já nos escalões inferiores, a necessidade será de informação quantitativa de baixo valor agregado, que possibilite o desempenho das tarefas rotineiras. A figura 4 apresenta um diagrama desta hierarquia das classes de informação.
FIGURA 3

A equação de valor da informação

VI - função (informação, organização, finalidade, ações e resultados)

FIGURA 4

Os níveis hierárquicos da informação

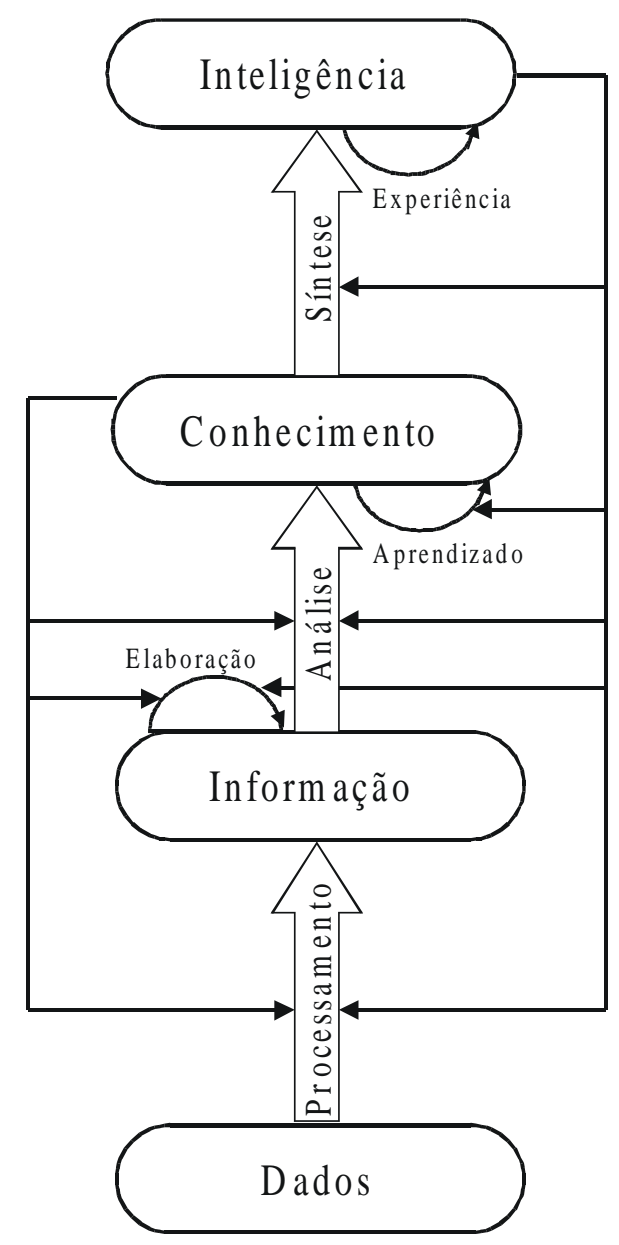

Dados compreendem a classe mais baixa de informação e incluem os itens que representam fatos, textos, gráficos, imagens estáticas, sons, segmentos de vídeo analógicos ou digitais etc. Os dados são coletados, por meio de processos organizacionais, nos ambientes interno e externo. Em suma, dados são sinais que não foram processados, correlacionados, integrados, avaliados ou interpretados de qualquer forma. Esta classe representa a matéria-prima a ser utilizada na produção de informações. 
A próxima classe é a da informação propriamente dita. Nesta classe, os dados passam por algum tipo de processamento para serem exibidos em uma forma inteligível às pessoas que irão utilizá-los. Processar dados inclui a revelação de fotografias de um filme, as transmissões de rádio transformadas em um formato de relatório padronizado, a exibição de arquivos de computador como texto ou gráfico em uma tela, a grade de coordenadas em um mapa etc. O processo de transformação envolve a aplicação de procedimentos que incluem formatação, tradução, fusão, impressão e assim por diante. A maior parte deste processo pode ser executada automaticamente.

Uma vez que dados tenham sido transformados em informações, pelo menos em uma interpretação inicial, é possível refinar as informações mediante um processo de elaboração. As informações resultantes deste processo incluem características adicionais do problema, geram hipóteses, conseqüências das hipóteses, sugerem soluções para problemas, explanação e justificativas de sugestões, crítica de argumentos etc. Portanto, a transformação de dados em informações deve ser vista, simplificadamente, como um tipo de pré-processamento de um processo de elaboração.

O próximo nível é o do conhecimento, que pode ser definido como sendo informações que foram analisadas e avaliadas sobre a sua confiabilidade, sua relevância e sua importância. Neste caso, o conhecimento é obtido pela interpretação e integração de vários dados e informações para iniciar a construção de um quadro de situação. O processo de transformação é realizado por meio de avaliação de dados e informações. Os insumos provenientes das diversas fontes são analisados e combinados na síntese de um produto final, o conhecimento. É por meio do conhecimento que aqueles que assessoram as decisões buscam uma compreensão mais efetiva da situação problema.

O conhecimento não é estático, modificando-se mediante a interação com o ambiente, sendo este processo denominado aprendizado. Uma visão mais ampla é que o aprendizado é a integração de novas informações em estruturas de conhecimento, de modo a torná-las potencialmente utilizáveis em processos futuros de processamento e de elaboração. Além disto, conhecimentos novos podem resultar de um processo de inferência na própria estrutura do conhecimento.
O nível mais alto desta hierarquia é a inteligência, que pode ser entendida como sendo a informação como oportunidade, ou seja, o conhecimento contextualmente relevante que permite atuar com vantagem no ambiente considerado. Também pode ser vista como o conhecimento que foi sintetizado e aplicado a uma determinada situação, para ganhar maior profundidade de consciência da mesma. Portanto, a inteligência resulta da síntese de corpos de conhecimentos, sendo usados julgamento e intuição daquele que toma decisões e obtida uma visualização completa da situação.

Idealmente, o entendimento de uma situação apóia o decisor na visualização do cenário e cria as condições para que o planejamento possa ser realizado e as ações efetivadas. Além disso, podem ser revelados fatores críticos em qualquer situação, possibilitando a antecipação a eventos, mediante o reconhecimento das conseqüências de desenvolvimentos novos ou iminentes ou dos efeitos de uma decisão. Por isso tudo, a inteligência deve ser a base do processo decisório, considerando que raramente é possível alcançar a compreensão total.

A transformação de conhecimento em inteligência é realizada por meio de síntese, sendo uma habilidade puramente humana baseada em experiência e intuição, que vai muito além da capacidade de qualquer sistema especialista ou de inteligência artificial. Síntese simplesmente não pode ser reduzida a procedimentos ou regras, por não considerarem o complexo.

Por fim, a experiência pode ser definida como a efetividade da inteligência de uma organização, que é aperfeiçoada pelas decisões tomadas e consideradas como geradoras de algum tipo de vantagem. Então, a experiência é uma agregação de valor ao processo decisório de uma organização, por refletir toda a sua capacitação para atuar com competitividade no seu ambiente externo.

\section{A EQUAÇÃO DE VALOR DE UM SISTEMA DE INFORMAÇÃO}

Para sobreviver no próximo século e não ser expulsa do mercado, uma empresa precisa fornecer valor superior aos seus clientes. Fornecer valor é dar aos clientes tudo o que eles querem e nada do que não querem; a melhor qualidade e os melhores preços, seja rápido e sirva o cliente com um sorriso! Os clientes atuais, sofisticados e atentos, fazem quatro julgamentos quando decidem fazer negócio com uma organização: (1) qualidade, (2) serviço, (3) custos e (4) tempo (Band, 1997). 
A percepção do valor não acontece apenas na demanda por produtos de consumo, mas atinge todas aquelas instituições e empresas que fornecem algum tipo de produto ou prestam serviços. Neste universo, podemos incluir o governo, o setor de educação, as organizações sem fins lucrativos, os sistemas de informação etc.

A demanda por maior valor em um sistema de informação, multimídia ou não, pode ser percebida pela qualidade dos serviços e produtos fornecidos. Portanto, é preciso qualificar estes quatro fatores dando enfoque particular à essência desse sistema, que é a informação. Estes fatores transformam-se em qualidade da informação, portifólio de produtos e serviços, custo e tempo de resposta. Um sistema de informação para fornecer valor superior deverá disponibilizar a seus clientes todos estes fatores simultaneamente. A equação apresentada na figura 5, que é metafórica, procura traduzir esta percepção de valor. Assim, o aumento do valor do sistema estará condicionado à maximização do numerador e à minimização do denominador.

Produto é qualquer coisa que possa ser oferecida a um mercado para aquisição ou consumo, sendo do tipo tangível ou intangível. O serviço é um produto intangível, sendo entendido como uma atividade ou benefício, que permite a satisfação, realização de desejos, necessidades e resolução de problemas de um cliente isolado, de grupo de clientes ou de uma organização, estando sua produção desvinculada de um benefício. Portanto, o portifólio de um sistema de informação compreenderá todos os produtos tangíveis (documentos, relatórios etc.) e intangíveis (indexação, recuperação etc.) relacionados à matéria-prima informação.

A tarefa de quantificar o valor destes produtos não é muito simples. Alguns atributos envolvidos nesse tipo de tarefa são (Silveira, 1989):

- exatidão (grau de liberdade do erro da informação);

- alcance (integralidade da informação);

- conveniência (relevância da informação);

- clareza (grau que a informação está livre de ambigüidade);

- oportunidade (tempo decorrido no ciclo produtivo da informação);

- acessibilidade (facilidade com que a informação pode ser obtida pelo consumidor).
FIGURA 5

A equação de valor de um sistema de informação

$$
\text { Valor }=\frac{\text { Portifólio (Produtos e Serviços) X Qualidade }}{\text { Custos X Tempo de Resposta }}
$$

\section{FIGURA 6}

O sistema de informação no contexto de uma organização (adaptado de Miranda, 1980).

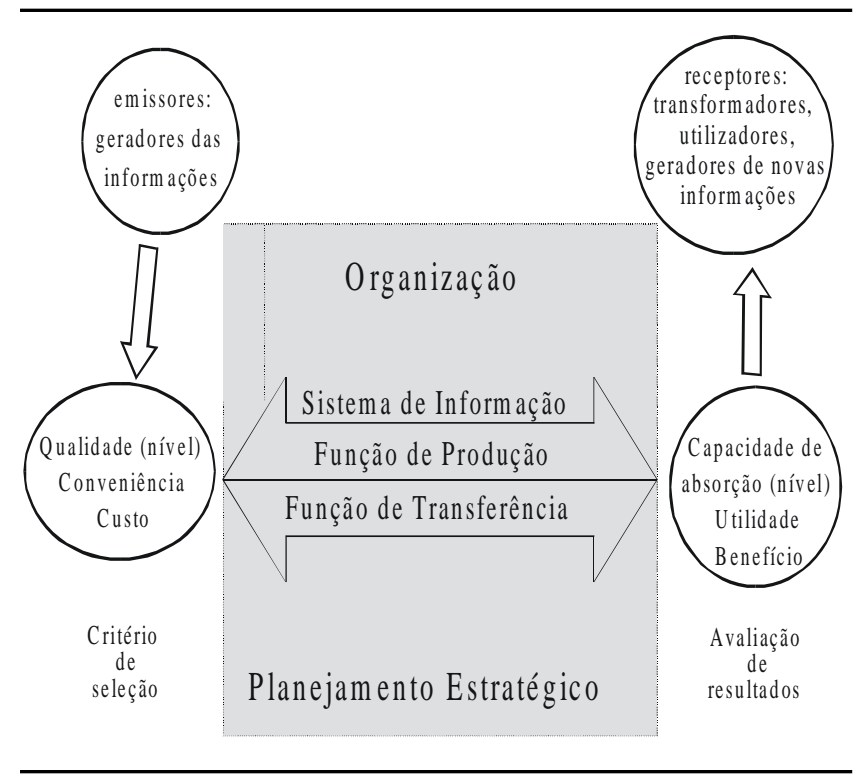

Essa autora também argumenta que a forma de apresentação dos produtos de informação interfere e influencia o valor deles junto aos consumidores. No caso dos sistemas de informação, o desenvolvimento de interfaces é um dos pontos críticos. É por meio da interface que o cliente perceberá o valor do sistema. Por isso, os clientes do sistema deverão estar familiarizados com o uso desses produtos. Caso contrário, deverão receber treinamento versando sobre as formas de acesso, formatação das telas de saída da informação, ferramentas de recuperação etc.

Além disso, é importante analisar as questões ligadas à transferência e à seleção da informação. Nesse sentido, é necessário considerar o seguinte: de um lado, está o emissor e, no outro extremo, o receptor da informação. Os sistemas de informação a que se ligam estão no centro da transferência, facilitando o acesso aos suportes de informação. Toda seleção de material informacional deve ser feita em função de seu uso e não, tão-somente, do armazenamento da informação (Miranda, 1980). A figura 6 apresenta uma ilustração deste papel do sistema de informação no contexto de uma organização. 
A seleção da informação deve atender às necessidades da organização, considerando as implicações constantes no Planejamento Estratégico de seu Sistema de Informação. Entre a seleção do material e a avaliação dos resultados, estão as funções de produção e de transferência do sistema de informação (Barreto, 1996). Assim, o sistema de informação associa a qualidade à capacidade de absorção, a conveniência à utilidade e o custo ao benefício, ou seja, permite a comunicação entre emissor e receptor.

Prosseguindo na análise da equação acima, pode-se afirmar que custo e qualidade são fatores interdependentes. Adotar cortes nos custos não vale a pena, se a qualidade for comprometida. As empresas modernas aprenderam que o foco na qualidade do produto também resulta em custos mais baixos - melhor valor para o cliente. Recentemente este termo tem se proliferado na descrição dos produtos e serviços, bem como nos métodos e processos que as organizações utilizam na sua obtenção. Mais do que uma moda, a qualidade é uma necessidade imposta pela crescente competitividade entre organizações e pela globalização dos mercados onde operam.

Qualidade é um conceito multidimensional que se realiza por meio de um conjunto de atributos ou características. Não pode ser definida universalmente, mas deve ser definida para o item em questão, o Sistema de Informação. Assim, qualidade em sistemas de informação é um conjunto de propriedades a serem atendidas, de modo que o sistema satisfaça as necessidades de seus usuários.

Uma das primeiras tarefas ao avaliar um sistema de informação é a identificação dos custos. Eles podem ser analisados quantitativa e qualitativamente. A verdadeira compreensão da dinâmica de custos envolve a documentação do relacionamento entre as atividades e suas causas e do relacionamento entre atividades e seus custos (Band, 1997).

A análise quantitativa avalia os custos relativos à implantação e ao custeio do sistema de informação. O primeiro refere-se a todas as despesas relativas ao planejamento, desenvolvimento e implantação de um sistema de informação. O outro será responsável pela manutenção do funcionamento do sistema durante todo o seu ciclo de vida. Estes tipos de custos podem ser identificados como aqueles que não agregam valor ao sistema, por serem relativos à sua vida vegetativa.

Já a análise qualitativa buscará identificar a contribuição global em relação às estratégias da organização. Este é um elemento-chave ao se tentar justificar a efetividade do sistema. O outro aspecto desta análise é identificação dos benefícios. A utilidade e a necessidade do sistema serão percebidas, se estes benefícios puderem ser quantificados e considerados relevantes (Fitzgerald, 1998). Caso contrário, o sistema deverá ser revisto e modificado, de modo a atender às expectativas da organização. Em suma, este tipo de análise focalizará o valor agregado fornecido pelo portifólio de produtos e serviços de um sistema de informação.

Ainda em relação aos benefícios, existem duas categorias básicas para justificação do valor da informação: aqueles casos em que os benefícios podem ser calculados e aqueles em que não podem. Os benefícios podem ser calculados quando o efeito na lucratividade, por alterar uma decisão, pode ser determinado. Neste caso, se o custo da informação adicional for menor que o aumento da lucratividade, a obtenção da informação terá seu custo justificado. $\mathrm{Na}$ maioria das vezes, os benefícios não podem ser mensuráveis. A dificuldade em avaliá-los é um dilema particularmente surpreendente, uma vez que existe uma tendência de se procurar ou receber mais informação que o necessário. Portanto, os fatores que afetam o custo da informação são os seguintes: precisão, oportunidade e freqüência de atualização (Wetherbe, 1987).

Finalmente, as empresas bem-sucedidas na década do valor atacarão o consumo de tempo na organização como um todo com a mesma intensidade que costumavam focalizar o custo (Band, 1997). Neste caso, o sistema de informação deverá responder às demandas em tempo real, o que significará disponibilizar informação com oportunidade. O tempo de resposta será, então, uma conseqüência natural da otimização dos outros fatores componentes da equação apresentada na figura 5 .

\section{O PLANEJAMENTO E A CADEIA DE VALOR DE UM SISTEMA DE INFORMAÇÃO}

Atualmente, a convergência das tecnologias da informação e dos sistemas de informação tem afetado os processos de trabalho das organizações. Assim, antes de implantar qualquer sistema desta natureza, é de vital importância desenvolver uma análise que permita determinar os principais requisitos do projeto. Esta análise deverá basear-se em metodologias específicas para o desenvolvimento de sistemas de informação.

Estas metodologias são classificadas freqüentemente de acordo com os temas ou características dos sistemas a serem desenvolvidos, podendo ser aplicadas às seguintes situações (Avison \& Taylor, 1997): 
- problema bem definido e bem estruturado e com objetivos claros;

- problema bem estruturado, com objetivos claros e incertezas quanto às necessidades dos usuários;

- problema não estruturado e os objetivos não são claros;

- grande interação do usuário com o sistema e/ou a aceitação do usuário é importante;

- complexas, em que há necessidade de uma abordagem contingencial para o desenvolvimento de sistemas de informação.

Esta última classe é a mais abrangente e a que atende à maioria das abordagens de desenvolvimento destes sistemas. Entretanto, cada situação terá a sua particularidade, e o analista deverá explorar ou criar uma metodologia que melhor se adapte à solução do problema.

O referencial multivisão (Avison \& Taylor, 1997), que consiste em uma abordagem contingencial, é mais adequada que as demais, por ser uma técnica exploratória neste tipo de atividade. Ela fornece um referencial que orienta o analista na escolha das técnicas e das ferramentas para a solução de qualquer situação-problema e também recomenda documentação e outras normas. Existem várias situações em que este método foi usado com sucesso.

A figura 7 apresenta uma ilustração da segunda versão do método multivisão. Os três primeiros estágios compreendem a análise organizacional (que examina o comportamento organizacional), análise e projeto sociotécnico (que examina os processos de trabalho) e o projeto e a implementação técnica (que examina a plataforma tecnológica). Estes estágios são integrados pela análise e modelagem da informação que atua como uma ponte entre os outros três, comunicando e ordenando os resultados entre cada um. Assim, este método apresenta um processo metodológico de aprendizado, em que as mudanças são constantes e ocorrem durante todo o desenvolvimento do sistema.

O planejamento e o desenvolvimento do sistema de informação de uma organização devem, então, resultar de uma análise que proporcione obter uma estimativa prévia sobre as seguintes dimensões:
FIGURA 7

O referencial multivisão (adaptado de Avison \& Taylor, 1997).

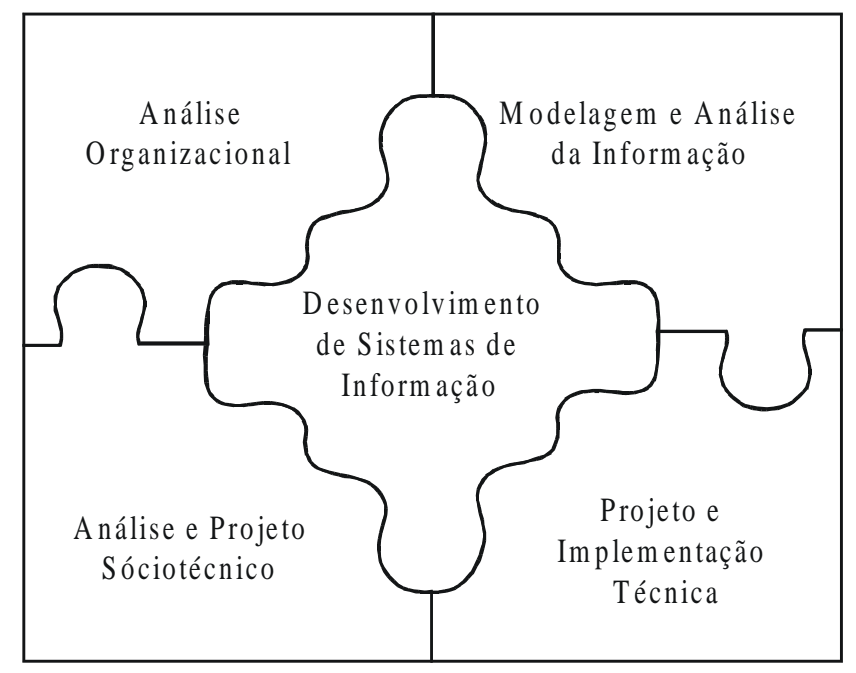

- estratégica: em que se analisa o impacto do sistema em relação ao ambiente externo da organização, incluindo aspectos relacionados à competitividade, posicionamento no ambiente, visão do cliente, diferencial de mercado etc.;

- organizacional: onde são analisados aspectos relativos às necessidades de informação da organização para a sua boa estruturação, coordenação operacional e atendimento às demandas externas;

- econômica: em que se incluem os aspectos relacionados com a sua importância econômica com especial atenção à redução de custos, melhorias de produtividade e eficiência, ganhos financeiros e outros aspectos que possam ser mensuráveis;

- capacitação da organização: refere-se ao cuidado quanto à capacitação em face do conjunto de tecnologias disponíveis, de forma que a organização esteja preparada para acompanhar as possibilidades de utilização e acomodar a evolução tecnológica.

Então, a cadeia de valor do sistema será uma conseqüência natural do planejamento realizado. O sistema deverá atender aos objetivos previstos, proporcionando melhoria e otimização do processo decisório, vantagem competitiva, aumento da lucratividade, melhor posicionamento no ambiente externo, melhor efetividade no gerenciamento da organização etc. A obtenção e manutenção destes aspectos é atualmente uma necessidade para a sobrevivência das organizações. 
A cadeia de valor será um instrumento básico para diagnosticar e determinar o uso da informação em apoio às decisões e ações no âmbito de uma organização. Mais objetivamente, a cadeia de valor pode ser definida como um conjunto de atividades executadas em um sistema de informação com a finalidade de produzir e transferir a informação, proporcionando sustentação ao processo decisório de uma organização. A figura 8 mostra um diagrama desta cadeia, onde as atividades de valor são os blocos relativos à produção e à transferência da informação.

A coleta de dados inclui todos os meios pelos quais a informação dá entrada no sistema. Eles podem ser coletados diretamente de fontes internas, no ambiente interno da organização, ou de fontes externas, no seu ambiente externo. Normalmente, os dados brutos coletados no ambiente externo têm pouco valor direto para a organização. Então, eles devem ser processados visando à transformação em uma forma mais útil. Em geral, este processamento inicial envolve a formatação, a agregação e a filtragem dos dados brutos, além da combinação com aqueles dados provenientes de fontes diferentes.

Uma das tarefas críticas de qualquer sistema de informação é a disponibilização da informação correta às pessoas certas e com oportunidade. Cada tomador de decisão dentro de uma organização necessita apenas de uma pequena porção de informação para apoiá-lo neste processo. O propósito da atividade de disseminação é determinar as necessidades de informação e disponibilizálas com oportunidade. Cada vez mais, esta atividade envolve a disponibilização da informação em diferentes formatos.

O propósito da etapa de modelagem e apresentação é combinar a informação proveniente de diversas fontes, transformando-a em uma forma útil e clara para apoiar o processo de decisão. Freqüentemente, esta transformação final e a apresentação da informação são inseparáveis, porque a forma final deve ser personalizada para atender a um cliente específico. A informação pode ser apresentada por meio de um dos seguintes modos:

- visualização de atividade corrente ou histórica: a modelagem consiste simplemente em agregar, resumir ou filtrar a informação para ser apresentada em um formato claro;

- prognóstico de atividade futura: a modelagem requer o uso de metodologias estatísticas que estimam valores futuros baseado nas informações atuais e históricas;
FIGURA 8

\section{A cadeia de valor de um sistema de informação}

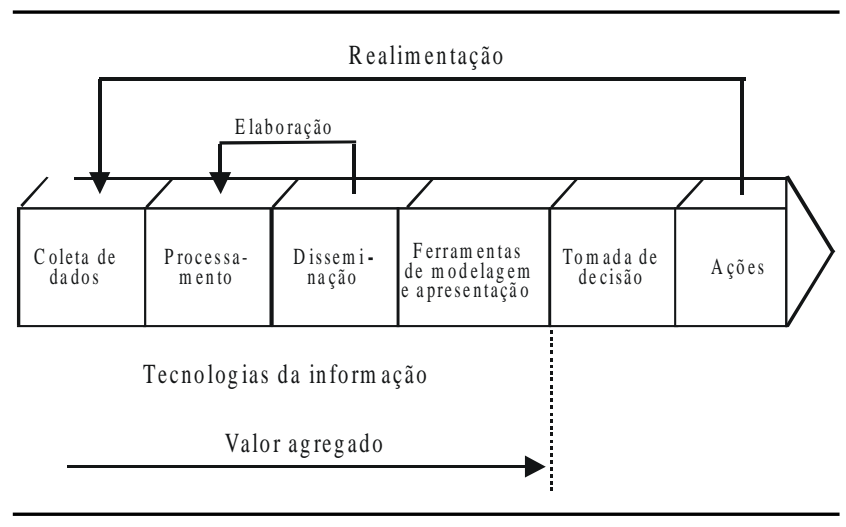

- simulação dos efeitos de diferentes decisões: o modelo de simulação pode ser tão simples quanto uma curva de demanda, que relaciona a demanda de um produto ao seu preço, ou ser um modelo complexo, que incorpora interações entre centenas ou milhares de variáveis;

- recomendação das melhores decisões: para sugerir a melhor decisão, um modelo de otimização deve procurar entre diferentes alternativas e determinar qual é a melhor, o que requer uma sofisticada modelagem matemática.

As decisões dentro de uma organização normalmente são tomadas por pessoas. Porém, em situações em que um grande número de decisões precisam ser implementadas muito rapidamente, pode ser empregado algum tipo de automação para viabilizar as decisões tomadas pelo computador. Exemplos incluem o comércio eletrônico, sistemas de controle de estoques, que fazem pedidos automaticamente quando o estoque atinge níveis predefinidos, e companhias aéreas, que gerenciam automaticamente as disponibilidades de assentos baseando-se na confirmação de reservas.

Uma vez tomadas as decisões, elas precisam ser efetivadas. É neste ponto que a organização percebe qualquer retorno da informação produzida. A partir das ações, o processo se reinicia para que novos dados possam ser coletados e seja possível executar uma avaliação das ações implementadas.

O fluxo da informação em uma organização é um processo de agregação de valor, e o sistema de informação pode ser considerado como a sua cadeia de valor, por ser o suporte para a produção e a transferência da informação. Assim, um sistema de informação é uma combinação de processos relacionados ao ciclo informacional, de pessoas e de uma plataforma de tecnologia da informação, organizados para o alcance dos objetivos de uma organização. 


\section{Eduardo Amadeu Dutra Moresi}

\section{CONCLUSÃO}

Uma vez analisado o valor da informação e do sistema de informação sob a perspectiva de uma organização, merecem destaque alguns pontos considerados relevantes. O valor da informação é uma função do contexto da organização, da finalidade de utilização, do processo decisório e dos resultados das decisões. No âmbito do processo decisório, a informação assume níveis hierárquicos distintos. $\mathrm{O}$ valor agregado cresce com grau de proporcionalidade direta em relação à pirâmide organizacional. Os altos escalões necessitarão de informação de alto valor agregado visando a obter uma visão global da situação, enquanto os escalões inferiores terão necessidade de baixo valor agregado, que atenda ao desempenho das tarefas rotineiras.

Os sistemas de informação têm sido desenvolvidos para otimizar o fluxo de informação relevante no âmbito de uma organização, desencadeando um processo de conhecimento e de tomada de decisão e intervenção na realidade. De modo geral, existe um consenso de que um sistema de informação deve ser estratégico e contribuir para que uma organização possa alcançar os seus objetivos (Rowley, 1995). Para isso, a abordagem metodológica no seu desenvolvimento deve ser voltada para a determinação das necessidades, a organização, a disseminação e a representação da informação, com o objetivo de otimizar a cadeia de valor do sistema.

Para concluir, é importante resumir os fatores fundamentais na percepção de valor da informação e de um sistema de informação:

- portifólio de produtos e serviços;

- confiabilidade e precisão das informações;

- transferência da informação entre emissor e receptor por intermédio do sistema de informação;

- oportunidade, quantidade e qualidade na disponibilização da informação;

- apoio ao processo decisório, melhorando a qualidade das decisões;

- considerar a informação como um recurso estratégico da organização;

- considerar a informação como instrumento de vantagem competitiva, diferencial de mercado e de lucratividade;

- tempo de resposta do sistema;

- relação custo-benefício;

- relação custo-efetividade.

\section{REFERÊNCIAS BIBLIOGRÁFICAS}

1. AMARAL, L.A.M. PRAXIS: um referencial para o Planeamento de Sistemas de Informação [on-line]. Tese de Doutorado apresentada na Universidade do Minho, Portugal, 1994. Available from Internet: http://shiva.di.uminho.pt/ amaral/amaral1.html; data de acesso: 22 Jun 98.

2. AVISON, D. E., TAYLOR, V. Information systems development methodologies: a classification according to problem situation. Journal of Information Systems, v. 12, n. 1, p.73-81, March 1997.

3. BAND, William A. Competências críticas: dez novas idéias para revolucionar a empresa. Rio de Janeiro: Campus, 1997.

4. BARRETO, Aldo de A. A eficiência técnica e econômica e a viabilidade de produtos e serviços de informação [online]. Mar 1996. Available from Internet: http://www.alternex.com.br/ aldoibct/pesquisa/; data de acesso: 22 Jun 98.

5. CHAUMIER, J. Systemes d'information: marché et technologies. Paris: Enterprise Moderne, 1986.

6. CHIAVENATO, Idalberto. Introdução à Teoria Geral da Administração. 5. ed. São Paulo: Makron Books, 1999.

7. CRONIN, Blaise. Esquemas conceituais e estratégicos para a gerência da informação. Revista da Escola de Biblioteconomia da UFMG, v. 19, n. 2, p. 195-220, Set 1990

8. DERTOUZOS, Michael L. O que será? como o mundo da informação transformará nossas vidas. São Paulo: Companhia das Letras, 1997.

9. DUSTDAR, Schahram \& ANGELIDES, Marios C. Organizational impacts of multimedia information systems. Journal of Information Technology, v. 12, n. 1, p. 33-43, March 1997.

10. FITZGERALD, Guy. Evaluating information systems projects: a multidimensional approach. Journal of Information Technology, v. 13, n. 1, p. 15-27, March 1998.

11. KIELGAST, Soeren, HUBBARD, Bruce A. Valor agregado à informação - da teoria à prática. Ciência da Informação on Line, Brasília, v. 26, n. 3, 1997. Available from Internet: http:// www.ibict.br/cionline; 11 Jan 98.

12. KING, J.L. \& KRAEMER, K. L. Information resource management: is it sensible and can it work? Information $\mathcal{E}$ Management, v. 15, n. 1, p. 7-14, 1988.

13. MIRANDA, Antônio. Estruturas de informação e análise conjuntural: ensaios. Brasília: Thesaurus, 1980.

14. ROWLEY, Jennifer. Strategic information systems planning. Information Services $\mathcal{E}$ Use, v. 15, n. 1, p. 57-66, 1995.

15. SARACEVIC, Tefko. Information Science. Journal of the American Society for Information Science, v. 50, n. 12, p. 1051-1-63, 1999.

16. SILVEIRA, Amélia. Marketing em Bibliotecas Universitárias: evolução, transferência de princípios e estudo da aplicação no Sistema Integrado de Bibliotecas da Universidade de São Paulo. Tese de Doutorado apresentada na Escola de Comunicações e Artes da USP, 1989.

17. URDANETA, I. P. Gestión de la inteligencia, aprendizaje tecnológico y modernización del trabajo informacional: retos y oportunidades. Caracas: Universidad Simón Bolivar, 1992.

18. VAN WEGEN, Bert \& DE HOOG, Robert. Measuring the economic value of information systems. Journal of Information Technology, v. 11, n. 3, p. 247-260, Sept 1996.

19. WETHERBE, James C. Análise de sistema para sistemas de informação por computador. 3a Ed. Rio de Janeiro: Campus, 1987. 